\title{
Pedunculated Focal Nodular Hyperplasia of the Liver
}

\author{
Alexandru Martiniuc ${ }^{1,2}$, Traian Dumitraşcu ${ }^{1,2}$ \\ "Carol Davila" University of Medicine and Pharmacy, Bucharest, Romania \\ ${ }^{2}$ Center of General Surgery and Liver Transplant, Fundeni Clinical Institute, Bucharest, Romania
}

\author{
Corresponding author: \\ Traian Dumitrascu, MD \\ "Carol Davila" University of Medicine \\ and Pharmacy, Center of General \\ Surgery and Liver Transplant \\ Fundeni Clinical Institute \\ Fundeni Street no 258, 022328 \\ Bucharest, Romania \\ E-mail: traian.dumitrascu@umfcd.ro
}

\section{ABSTRACT}

Focal nodular hyperplasia $(\mathrm{FNH})$ is the second most common type of benign liver tumour, and it is more frequently encountered in young women and the right hemi-liver. Most patients are asymptomatic, and there is no malignant potential. Thus, the current guidelines do not recommend any treatment for uncomplicated FNH, and surgery is indicated only for some atypical patients (with complications or uncertain diagnosis). Pedunculated forms are atypical, rare features of FNH and appear to be more frequently associated with complications. We hereby report the case of a 40 -year-old woman diagnosed at computed tomography with a lobulated subhepatic FNH with a long pedicle originating from segment III of the liver, which was successfully resected. Pedunculated FNH is associated with a challenging diagnosis and may require resection in order to avert potential complications such as compression of surrounding organs or torsion of the pedicle.

Key words: focal nodular hyperplasia; pedunculated liver tumour; liver resection

\section{INTRODUCTION}

Focal nodular hyperplasia (FNH) is the second most common type of benign liver tumour, and it is more frequently encountered in young women and the right hemi-liver $(1,2)$. The prevalence of $\mathrm{FNH}$ in the general population, assessed by transabdominal ultrasound, was recently reported to be $0.2 \%$ (3).

Most patients with FNH are asymptomatic (2). Furthermore, there is no malignant potential for FNH (2). Thus, the current guidelines of the European Association for the Study of the Liver do not recommend any treatment for FNH, except for particular (atypical) cases such as pain, haemorrhage, expanding or pedunculated/ exophytic FNH or when the diagnosis of hepatocellular adenoma or carcinoma cannot be ruled out (1). It is worth to mention that a recent study has shown that the progressive enlargement of FNH does not appear to be an indication for liver resection (4).

Thus, FNH is an uncommon indication for liver resection, and the number of liver resections for FNH has decreased in recent years (5). Most patients resected for FNH required minor liver resections and the main indications were 
diagnostic uncertainty and tumour-related symptoms $(6,7)$. The Fundeni Clinical Institute experience of 3165 liver resections performed between 2000 and 2016 included only 91 patients with $\mathrm{FNH}$ (3.3\% of the total number of liver resections)(8).

The imaging methods for diagnosis of $\mathrm{FNH}$ include ultrasound (gray-scale, color or power Doppler, contrast-enhanced) and multiphasic computed tomography and magnetic resonance imaging $(1,2,9)$. The five major criteria for FHN FNH are attenuation or signal intensity similar to that of the surrounding liver, homogeneity, strong enhancement without washout at in the arterial phase, the presence of a central scar, and the absence of a capsule (with or without a lobulated aspect) (9). An atypical imaging aspect is widely considered an indication for surgery in FNH (10).

We hereby present the case of a patient with a rare atypical case of $\mathrm{FNH}$ - an extrahepatic, pedunculated liver tumour of segment III.

\section{CASE PRESENTATION}

A 40-year-old woman with no significant medical history was admitted to our hospital for the evaluation of an asymptomatic inter-hepatic-gastric mass detected incidentally at ultrasound examination during a routine check-up. Routine laboratory tests were within normal limits, including the hepatitis B and C virus tests and CA 19-9, alpha-fetoprotein and carcinoembryonic antigen serum levels. Contrast-enhanced computed tomography revealed a lobulated solitary subhepatic mass, measuring $42 \mathrm{~mm} \times 50 \mathrm{~mm}$, arising from segment III of the liver, with a long pedicle (fig. 1).

The patient underwent surgery in March 2016. Intraoperatively a lobulated exophytic tumour mass originating from segment III of the liver with a long pedicle was identified and resected trough a minilaparotomy (fig. 2). The postoperative outcome was uneventful, and the patient was discharged on postoperative day 3.

Gross pathology examination of the operative specimen revealed a firm nodular lobulated browngrey tumour with central scar (fig. 3). The pathological finding was compatible with the diagnosis of FNH.

\section{DISCUSSION}

Pedunculated liver tumours are very uncommon $(10,11)$ and usually the pedicle remains undetected with imaging techniques (9). The imaging features of pedunculated liver tumours are similar to those of the usual intrahepatic tumours, except for their
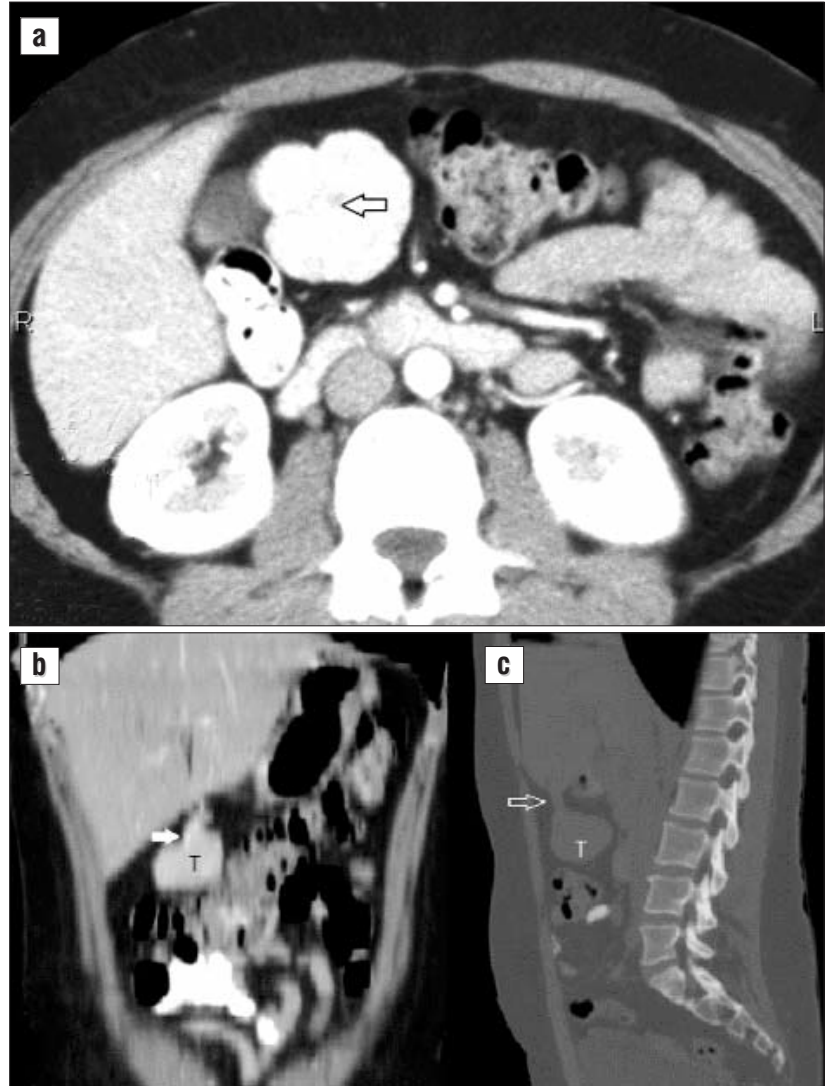

Figure 1 - Computed tomography (a) axial plane, arterial phase showing a homogeneous subhepatic lobulated mass (T), on the left side of the gallbladder, with strong contrast enhancement and with hypoattenuating central scar (black open arrow); (b) frontal plane, portal phase showing an isoattenuated subhepatic lobulated mass (T), and the drainage vein of the tumour (white filled arrow), at the level of the pedicle, originating from segment III of the liver;

(c) sagittal plane, non-enhanced, showing a homogeneous subhepatic lobulated mass ( $\mathrm{T}$ ) with pedicle (white open arrow) originating from segment III of the liver with an intensity similar to that of the liver

Figure 2 - Intraoperative aspects are showing a pedunculted lobulated tumour with long pedicle (white open arrow), originating from segment III of the liver (Sill)

(the white filled arrow marks the round ligament of the liver)

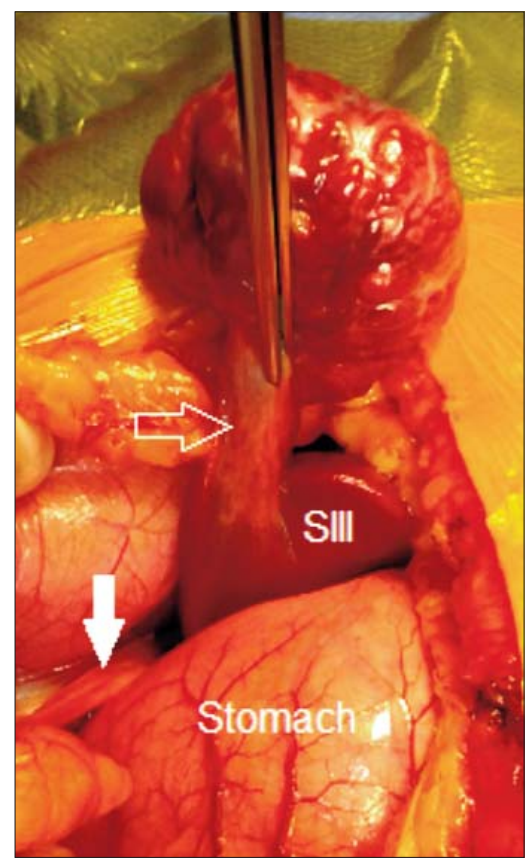




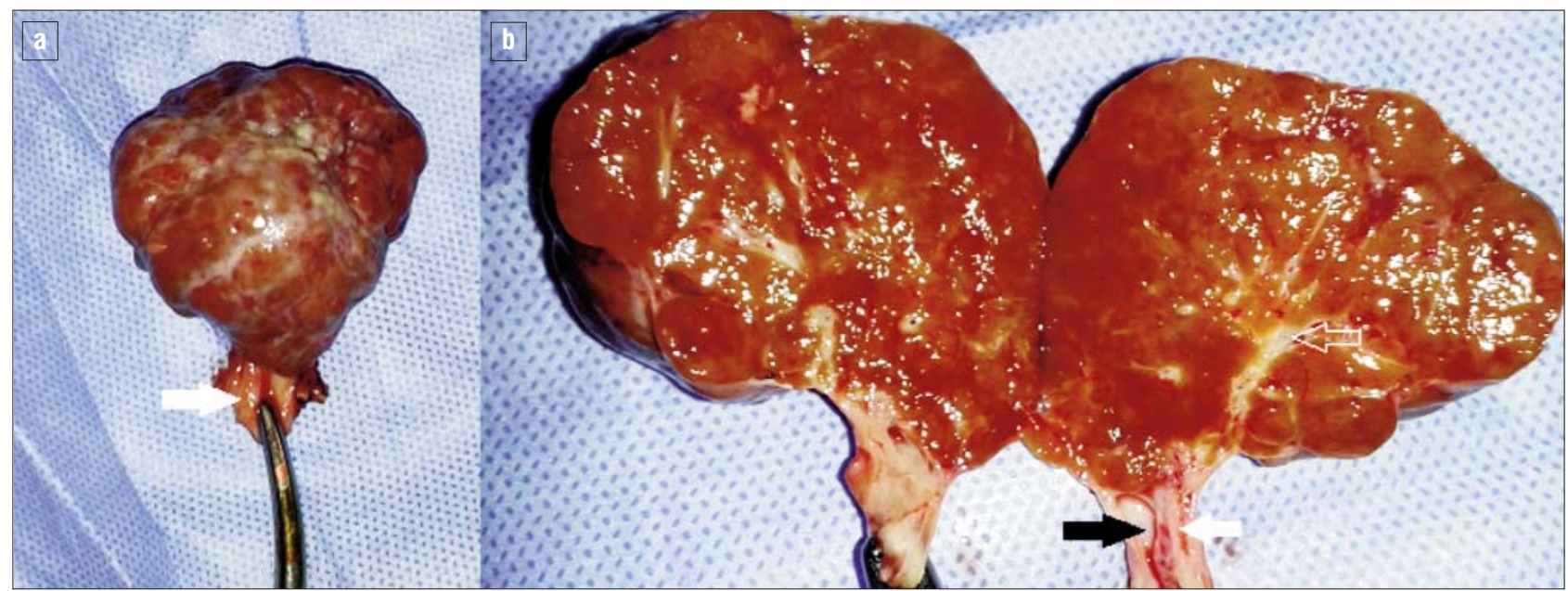

Figure 3 - Gross pathological appearance of the operative specimen showing (a) firm nodular lobulated brown-grey tumour with a pedicle (white filled arrow), (b) central scar (white open arrow), feeding artery (white filled arrow) and drainage vein of the tumour

(black filled arrow)

location (11). In our patient, the pedicle was identified at computed tomography, and there were typical imaging features of FNH except for the extrahepatic location.

Exophytic patterns of liver tumours were previously described for liver haemangioma (12), adenoma (13), focal nodular hyperplasia $(10,14,15)$, angiomyolipoma (16), solitary fibrous tumour (17), hepatocellular carcinoma (18), cholangiocarcinoma (19) and metastases (20).

Pedunculated forms were reported in approximately $9 \%$ of patients diagnosed with FNH (9) and appeared to be more frequently associated with haemorrhagic complications (2).

The diagnosis of a pedunculated $\mathrm{FNH}$ is challenging because they can be misdiagnosed as other intraabdominal tumours, such as Extra-gastrointestinal Stromal Tumours(14).

Thus, most patients will require resection for a precise diagnosis and to prevent particular complications such as torsion of the pedicle or compression of the surrounding organs.

\section{CONCLUSION}

$\mathrm{FNH}$ is a benign liver tumour that usually does not require surgery. For the rare forms of pedunculated $\mathrm{FNH}$, the diagnosis is challenging and may require resection for the uncertainty of diagnosis and potential complications, such as compression of surrounding organs or torsion of the pedicle.

\section{REFERENCES}

1. EASL Clinical Practice Guidelines on the management of benign liver tumours. J Hepatol 2016;65(2):386-98.

2. Nahm CB, Ng K, Lockie P, Samra JS, Hugh TJ. Focal nodular hyperplasia-a review of myths and truths. J Gastrointest Surg. 2011; 15(12):2275-83. doi: 10.1007/s11605-011-1680-x.

3. Kaltenbach TE, Engler P, Kratzer W, Oeztuerk S, Seufferlein T, Haenle $\mathrm{MM}$, et al. Prevalence of benign focal liver lesions: ultrasound investigation of 45,319 hospital patients. Abdom Radiol (NY) 2016; 41(1):25-32.

4. Broker MEE, Klompenhouwer AJ, Gaspersz MP, Alleleyn AME, Dwarkasing RS, Pieters IC, et al. Growth of Focal Nodular Hyperplasia is Not a Reason for Surgical Intervention, but Patients Should be Referred to a Tertiary Referral Centre. World J Surg 2017 Nov 22. doi: 10.1007/s00268-017-4335-6. [Epub ahead of print]

5. Hau HM, Atanasov G, Tautenhahn HM, Ascherl R, Wiltberger G, Schoenberg MB, et al. The value of liver resection for focal nodular hyperplasia: resection yes or no? Eur J Med Res 2015;20:86.

6. Navarro AP, Gomez D, Lamb CM, Brooks A, Cameron IC. Focal nodular hyperplasia: a review of current indications for and outcomes of hepatic resection. HPB (Oxford) 2014;16(6):503-11.

7. Perrakis A, Vassos N, Grutzmann R, Croner RS. What is Changing in Indications and Treatment of Focal Nodular Hyperplasia of the Liver. Is There Any Place for Surgery? Ann Hepatol 2017;16(3):33341.

8. Botea F, Ionescu M, Brasoveanu V, Hrehoret D, Alexandrescu S, Grigorie M, et al. Liver Resections in a High-Volume Center: Form Standard Procedures to Extreme Surgery and Ultrasound-guided Resections. Chirurgia (Bucur) 2017;112(3):259-77.

9. Dioguardi BM, Ronot M, Salvaggio G, Vilgrain V, Brancatelli G. Imaging of Hepatic Focal Nodular Hyperplasia: Pictorial Review and Diagnostic Strategy. Semin Ultrasound CT MR 2016;37(6):511-24.

10. Badea R, Meszaros M, Al HN, Rusu I, Chiorean L. Benign nodular hyperplasia of the liver-pedunculated form: diagnostic contributions of ultrasonography and consideration of exophytic liver tumors. J Med Ultrason (2001) 2015;42(1):97-102.

11. Kim HJ, Lee DH, Lim JW, Ko YT, Kim KW. Exophytic benign and malignant hepatic tumors: CT imaging features. Korean J Radiol 2008:9(1):67-75.

12. Zhang $X$, Zhou Z. Hepatic hemangioma masquerading as a tumor 
originating from the stomach. Oncol Lett 2015;9(3):1406-8.

13. Portinari M, Liboni A, Feo CV. Strangulated adenoma of the liver: a unique cause of acute abdomen. Ann Ital Chir 2014;85(ePub). pii: S2239253X14022439

14. Reddy K, Hooper K, Frost A, Hebert-Magee S, Bell W, Porterfield JR, et al. Pedunculated focal nodular hyperplasia masquerading as perigastric mass identified by EUS-FNA. Gastrointest Endosc 2015; 81(1):238-9.

15. Wasif N, Sasu S, Conway WC, Bilchik A. Focal nodular hyperplasia: report of an unusual case and review of the literature. Am Surg 2008;74(11):1100-3

16. Akatsu T, Sakamoto M, Shimazu M, Kitajima M. Pedunculated angiomyolipoma of the liver with a predominant pelioid pattern. Virchows Arch 2004;444(5):467-9.

17. Park HS, Kim YK, Cho BH, Moon WS. Pedunculated hepatic mass. Liver Int 2011;31(4):541.

18. Yeh CN, Lee WC, Jeng LB, Chen MF. Pedunculated hepatocellular carcinoma: clinicopathologic study of 18 surgically resected cases. World J Surg 2002;26(9):1133-8.

19. Noh SJ, Lee HK, Yu HC, Moon WS. Exophytic combined hepatocellular carcinoma and cholangiocarcinoma. Clin Mol Hepatol 2012; 18(4):416-9.

20. Nagata $\mathrm{H}$, Hayashi K, Mike M. An exophytic hepatic metastasis of mucinous colon cancer. Jpn J Clin Oncol 2015;45(6):605-6. 